\title{
Motor Evoked Potentials of Trunk Muscles in Traumatic Brain Injury Patients
}

\author{
Min-Ho Seo, M.D., Sung-Hee Park, M.D., Myoung-Hwan Ko, M.D., Jeong-Hwan Seo, M.D.
}

Department of Physical Medicine and Rehabilitation, Institute for Medical Sciences, Chonbuk National University Medical School, Research Institute of Clinical Medicine, Chonbuk National University Hospital, Jeonju 561-180, Korea

Objective To evaluate the motor innervation of trunk muscles in traumatic brain injury patients.

Method Twenty patients (12 men and 8 women) with traumatic brain injury were enrolled in this study. Their mean age was 41 years. Motor evoked potentials (MEPs) were performed on the motor cortex. Electromyographic activities were recorded from the bilateral rectus abdominis muscles, the external oblique abdominal muscles, and the 4th and 9th thoracic erector spinae muscles. The onset latency and amplitude of contralateral and ipsilateral MEPs were measured. All patients were assessed by the Korean version of the Berg Balance Scale (K-BBS) to investigate the relationship between the frequency of MEPs in trunk muscles and gait ability.

Results The mean frequency of ipsilateral MEPs was $23.8 \%$ with more damaged hemisphere stimulation, while the contralateral MEPs showed a mean frequency of $47.5 \%$ with more damaged hemisphere stimulation in traumatic brain injury patients. The latencies and amplitudes of MEPs obtained from the more damaged hemisphere were not significantly different from those of the less damaged hemisphere. There was no correlation between the manifestation of MEPs in trunk muscles and gait ability.

Conclusion The ipsilateral and contralateral corticospinal pathways to trunk muscles are less likely to be activated in traumatic brain injury patients because of direct injury of the descending corticospinal motor tract or decreased excitability of the corticospinal tract from prefrontal contusion.

Key Words Transcranial magnetic stimulation, Traumatic brain injury, Motor Evoked potential

\section{INTRODUCTION}

Trunk muscles play an important role in postural stability and have a significant effect on the recovery of

Received June 4, 2010; Accepted April 19, 2011

Corresponding author: Sung-Hee Park

Department of Physical Medicine and Rehabilitation, Chonbuk National University Medical School, San 2-20, Keumam-dong, Dukjin-gu, Jeonju 561-180, Korea

Tel: +82-63-250-2299, Fax: +82-63-254-4145, E-mail: shpark0130@jbnu. ac.kr

(c) This is an open-access article distributed under the terms of the Creative Commons Attribution Non-Commercial License (http://creativecommons.org/ licenses/by-nc/3.0) which permits unrestricted noncommercial use, distribution, and reproduction in any medium, provided the original work is properly cited. Copyright () 2011 by Korean Academy of Rehabilitation Medicine balance and gait abilities in patients with central nervous system (CNS) injuries such as stroke or spinal cord injury. ${ }^{1,2}$ Recently, a few studies have reported that trunk muscle strength is related to balance and functional impairment in stroke patients. ${ }^{3,4}$ In their neurophysiological study of the motor innervation patterns of trunk muscles, Fugiwara et al. ${ }^{5}$ reported that the recovery of trunk function was associated with an increase in ipsilateral motor evoked potentials (MEPs) in trunk muscles with the transcranial magnetic stimulation (TMS) in stroke patients. Park et al. ${ }^{6,7}$ reported a MEPs study of trunk muscles with the TMS in normal subjects and stroke patients. However, to our knowledge, there are 
no studies that have identified the association between trunk muscle function and motor control of trunk muscles by electrophysiologic techniques in patients with traumatic brain injury (TBI). Accordingly, we carried out a MEPs study with TMS in patients with TBI to identify the relationship between motor innervation patterns of trunk muscles and the clinical performance of trunk muscle in patients with traumatic TBI.

\section{MATERIALS AND METHODS}

\section{Subjects}

This study was performed on 20 patients treated for hemiplegia or quadriplegia caused by TBI. The subjects included those who visited the Department of Rehabilitation Medicine in our hospital between November 2007 and July 2009. The study excluded patients with severe aphasia or cognitive impairments swho were uncooperative, patients with severe medical or surgical illness, patients with neurologic deficits other than brain damage, patients with hemispatial neglect, patients with a vestibular or orthopedic problem affecting their balance ability, and patients with a recent onset of back pain or musculoskeletal disorder.

The Transcranial Magnetic Stimulation Adult Safety Screen (TASS) ${ }^{8}$ was used in patients for the selection of subjects. They were fully informed of mental or physical harm which could be caused during their participation in the study, and informed consent was obtained from subjects and their care-givers. The subjects in this study consisted of a total of 20 TBI patients (mean age $=41 \pm 17$ years; 12 men and 8 women), and the mean duration from the onset of injury to the date of exam was $27 \pm 19$ months (Table 1). Multiple brain lesions were frequently observed on both hemispheres in the TBI patients. Therefore, in this report, the cerebral hemispheres of ipsilateral

Table 1. Demographic and Clinical Characteristics of Patients

\begin{tabular}{ccccclc}
\hline Number & Sex & $\begin{array}{c}\text { Age } \\
\text { (years) }\end{array}$ & $\begin{array}{c}\text { Interval }^{*} \\
\text { (months) }\end{array}$ & $\begin{array}{c}\text { K-BBS } \\
\text { score }\end{array}$ & \multicolumn{1}{c}{$\begin{array}{c}\text { Lesions } \\
\text { hemisphere }\end{array}$} \\
\hline P1 & F & 27 & 9 & 49 & Left frontal lobe ICH, DAI & Left \\
P2 & F & 58 & 30 & 48 & Both F-T SDH, DAI & Left \\
P3 & F & 42 & 45 & 21 & Left F-P ICH & Right \\
P4 & F & 63 & 32 & 2 & Right basal ganglia ICH, DAI & Right \\
P5 & M & 42 & 8 & 31 & Both frontal ICH, pons ICH & Right \\
P6 & M & 44 & 38 & 45 & Both frontal ICH, DAI & Left \\
P7 & M & 38 & 14 & 49 & Both frontal ICH, DAI & Left \\
P8 & F & 33 & 6 & 52 & Both parietal SDH, DAI & Left \\
P9 & F & 23 & 58 & 51 & Left F-P ICH & Right \\
P10 & M & 54 & 45 & 43 & Right F-T-P ICH & Left \\
P11 & M & 42 & 57 & 53 & Left frontal SAH, Right F-T-P EDH & Left \\
P12 & F & 54 & 6 & 6 & Left T-P EDH, Right T-P SDH & Left \\
P13 & F & 56 & 16 & 49 & Both frontal SAH, Right frontal ICH & Left \\
P14 & M & 50 & 9 & 52 & Left F-T SDH, Right F-T SAH, SAH & Left \\
P15 & M & 21 & 34 & 10 & Left F-T-P SDH, Right frontal SDH & Left \\
P16 & M & 17 & 39 & 54 & Left temporal SAH, DAI & Right \\
\hline P17 & M & 16 & 2 & 23 & Both F-T ICH & Left \\
P18 & M & 17 & 14 & 49 & Both frontal lobe ICH, DAI & Left \\
P19 & M & 75 & 23 & 48 & Left temporal ICH, Right F-T SDH & Right \\
\hline P20 & M & 45 & 54 & 3 & Right frontal lobe, basal ganglia ICH & \\
\hline
\end{tabular}

F: female, M: male, P: Patient, ICH: Intracranial hemorrhage, SDH: Subdural hemorrhage, F: Frontal lobe, T: Temporal lobe, P: Parietal lobe, SAH: Subarachnoid hemorrhage, DAI: Diffuse axonal injury, K-BBS: Korean version of Berg balance scale

*Interval between the onset of traumatic brain injury and the participation in the study 
and contralateral to the paretic body side were defined as less damaged and more damaged hemispheres, respectively.

\section{Methods}

The study used a Medtronic Keypoint ${ }^{\circledR}$ electromyography device (Medtronic Inc., Skovlunde, Denmark). The sensitivity was adjusted to range from $50 \mu \mathrm{V}$ to $1 \mathrm{mV}$ per division with a 2-2,000 $\mathrm{Hz}$ selected, and the sweep rate was set to $50 \mathrm{~ms}$. The subjects were tested with their eyes open in a relaxed supine position. MEPs in trunk muscles were measured from rectus abdominis muscles, external oblique abdominal muscles, and erector spinae muscles ${ }^{5-7}$ Electromyographic activities were recorded from both sides with surface electrodes. The active electrodes were placed on the designated region, and reference and ground electrodes were placed

Table 2. Electrode Placement for Electromyographic Recording of Trunk Muscles

\begin{tabular}{ll}
\hline \multicolumn{1}{c}{ Muscle } & \multicolumn{1}{c}{ Electrode placement* } \\
\hline $\begin{array}{l}\text { Rectus } \\
\text { abdominis }\end{array}$ & $\begin{array}{l}\text { Active: } 3 \mathrm{~cm} \text { lateral to the umbilicus } \\
\text { Reference: over the costal margin to the } \\
\text { rib cartilage }\end{array}$ \\
$\begin{array}{ll}\text { External } \\
\text { oblique }\end{array}$ & $\begin{array}{l}\text { Active: } 15 \mathrm{~cm} \text { lateral to the umbilicus, } \\
\text { anterior to axillary line } \\
\text { Reference: anterior superior iliac spine }\end{array}$ \\
$\begin{array}{ll}\text { 4th thoracic } \\
\text { erector spinae }\end{array}$ & $\begin{array}{l}\text { Active: } 5 \mathrm{~cm} \text { lateral to T4 spinous process } \\
\text { Referen } \text { T4 spinous process }\end{array}$ \\
$\begin{array}{l}\text { 9th thoracic } \\
\text { erectors pinae }\end{array}$ & $\begin{array}{l}\text { Active: } 5 \mathrm{~cm} \text { lateral to T9 spinous } \\
\text { process } \\
\text { Reference: T9 spinous process }\end{array}$ \\
\hline
\end{tabular}

*All measures are approximate and taken into account anthropometric differences between subjects at a distance of at least $5 \mathrm{~cm}$ from the active electrodes and on the sternum, respectively (Table 2). Transcranial magnetic stimulation was performed with a Medtronic Magpro $^{\circledR}$ stimulator (Medtronic Inc., Skovlunde, Denmark) and a $70 \mathrm{~mm}$ diameter butterfly-shaped coil in the right and left optimal stimulus positions.

The coil was held tangential to the scalp, with the handle angled backwards and 45 degrees away from the midline. The scalp sites of stimulation were determined using a fitting cap, pre-marked with sites at $1 \mathrm{~cm}$ spacing in a latitude-longitude coordinate system. Threshold was defined, as the minimum stimulation intensity required to evoke a peak-to-peak motor evoked potentials (MEPs) of more than $50 \mu \mathrm{V}$ in at least five out of ten consecutive trials. Threshold was determined using $5 \%$ increments of stimulator outputs from $30 \%$ maximal stimulus intensity. The inter-stimulus interval was adjusted to over 10 seconds, and the stimulating coil temperature was set to not exceed $35^{\circ} \mathrm{C}$. The maximum magnetic field strength was 2.0 Tesla.

Stimulus intensity was set at threshold plus $20 \%$ of maximum stimulator output. The MEP latency was determined as the shortest onset latency and the amplitude was obtained by averaging values from four stimuli. The study observed the frequency of ipsilateral and contralateral MEPs elicited by sequential stimulation of less damaged and more damaged hemispheres and measured the latencies and amplitudes of the MEPs. The gait ability was assessed by the Korean version of the Berg balance scale (K-BBS), ${ }^{9}$ and cognitive function was assessed by the Korean-mini mental state examination (K-MMSE).

SPSS version 13.0 for Windows (Chicago, USA) was used for statistical analysis, and Fisher's exact test was

Table 3. Percentage of Patients with Ipsilateral and Contralateral MEPs Obtained by Stimulation of More Damaged and Less Damaged Hemisphere

\begin{tabular}{lcccc}
\hline & \multicolumn{2}{c}{ Less damaged hemisphere } & \multicolumn{2}{c}{ More damaged hemisphere } \\
\cline { 2 - 5 } & Ipsi-MEP & Cont-MEP & Ipsi-MEP & Cont-MEP \\
\hline Rectus abdominis $(\mathrm{n}=20)$ & $20 \%^{*}$ & $65 \%^{*}$ & $35 \%$ & $45 \%$ \\
External oblique $(\mathrm{n}=20)$ & $20 \%^{*}$ & $60 \%^{*}$ & $20 \%$ & $45 \%$ \\
4th thoracic erector spinae $(\mathrm{n}=20)$ & $25 \%$ & $60 \%$ & $25 \%$ & $50 \%$ \\
9th thoracic erector spinae $(\mathrm{n}=20)$ & $20 \%^{*}$ & $55 \%^{*}$ & $15 \%^{*}$ & $50 \%^{*}$ \\
\hline Mean & $21.3 \%$ & $60.0 \%$ & $23.8 \%$ & $47.5 \%$ \\
\hline
\end{tabular}

n: number of patients, MEP: Motor evoked potential, Ipsi: Ipsilateral, Cont: Contralateral

${ }^{*} \mathrm{p}<0.05$, Fisher's exact test between Ipsi-MEPs and 'Cont'-MEPs 
performed to analyze the frequency of obtained ipsilateral and contralateral MEPs in each trunk muscles. The Mann-Whitney U test was used to compare frequency of MEPs recordings between two groups which assigned to the K-BBS scores. The Wilcoxon signed-rank test, a nonparametric statistical technique, was used to compare the electrophysiologic parameters of the contralateral MEPs from TMS of each hemispheres. An inter-group difference of K-MMSE scores by gait ability was analyzed using the Mann-Whitney U test. p-values less than 0.05 were considered statistically significant.

\section{RESULTS}

\section{Manifestation of MEPs in the subjects}

The contralateral MEPs in all trunk muscles with the less damaged hemisphere stimulation showed the mean frequency of $60.0 \%$, while the mean frequency of ipsilateral MEPs was 21.3\%. The frequency of contralateral MEPs was significantly higher than that of ipsilateral MEPs in rectus abdominis muscles, external oblique abdominal muscles, and 9th thoracic erector spinae muscles $(\mathrm{p}<0.05)$. The mean contralateral and ipsilateral MEPs with more damaged hemisphere stimulation in the 20 subjects showed a frequency of $47.5 \%$ and $23.8 \%$, respectively. The frequency of contralateral MEPs with more damaged hemisphere stimulation was significantly higher than that of ipsilateral MEPs only in the 9th thoracic erector spinae muscles $(\mathrm{p}<0.05)$ (Table 3$)$.

The frequency of contralateral MEPs with less damaged hemisphere stimulation was higher than of contralateral MEPs with more damaged hemisphere stimulation, but the difference was not statistically significant ( $p>0.05)$. There was no statistically significant difference in frequency between ipsilateral MEPs more damaged hemisphere stimulation and less damaged hemisphere stimulation ( $p>0.05$ ) (Table 3 ).

Frequencies of ipsilateral and contralateral MEPs in the sujects with MEPs evoked

We assumed that the subjects with no MEPs might be due to serious damage to the corticospinal tract of the trunk muscles and theses subjects were inappropriate to evaluate the excitability of the corticospinal pathways. Therefore, we exclude these subjects in the present analysis.

In order to identify the activities of ipsilateral and contralateral motor pathways, the ipsilateral and contralateral MEPs were compared in terms of frequency, except in cases where no MEP was evoked due to serious damage to the motor pathways of trunk muscles. MEPs in each trunk muscles were evoked in 12-13 subjects (60-65\%) with less damaged hemisphere stimulation and 10 subjects $(50 \%)$ with more damaged hemisphere stimulation. In subjects with MEPs evoked, the contralateral MEPs were manifested at $90 \%$ or more in both the more damaged and less damaged hemisphere stimulation. In the rectus abdominis muscles, external oblique abdominal muscles, and 4th thoracic erector spinae muscles, the ipsilateral MEPs appeared at a higher frequency with more damaged hemisphere stimulation than less damaged hemisphere stimulation $(p>0.05)$ (Table 4).

\section{Latencies and amplitudes of MEPs}

In the cases of MEPs evoked, the latency of contralateral MEPs with more damaged hemisphere stimulation had tendency to be prolonged than that of ones with less damaged hemisphere stimulation. However, it is not possible to directly compare the latency of MEPs between

Table 4. Percentage of Ipsilateral and Contralateral MEPs by Patients Responded to Magnetic Stimulation over Cortical Hemisphere

\begin{tabular}{lcccccc}
\hline & \multicolumn{3}{c}{ Less damaged hemisphere } & \multicolumn{3}{c}{ More damaged hemisphere } \\
\cline { 2 - 7 } & Ipsi-MEP & Cont-MEP & Total (n) & Ipsi-MEP & Cont-MEP & Total (n) \\
\hline Rectus abdominis & $31 \%$ & $100 \%$ & 13 & $70 \%$ & $90 \%$ & 10 \\
External oblique & $33 \%$ & $100 \%$ & 12 & $40 \%$ & $90 \%$ & 10 \\
4th thoracic erector spinae & $38 \%$ & $92 \%$ & 13 & $50 \%$ & $100 \%$ & 10 \\
9th thoracic erector spinae & $33 \%$ & $91 \%$ & 12 & $30 \%$ & $100 \%$ & 10 \\
Mean & $33.8 \%$ & $95.8 \%$ & & $47.5 \%$ & $95 \%$ & \\
\hline
\end{tabular}

n: number of patients, MEP: Motor evoked potential, Ipsi: Ipsilateral, Cont: Contralateral 
Table 5. Latency of Ipsilateral and Contralateral MEPs Obtained by Stimulation of More Damaged and Less Damaged Hemisphere

\begin{tabular}{llccc}
\hline & \multicolumn{2}{c}{ Less damaged hemisphere } & \multicolumn{2}{c}{ More damaged hemisphere } \\
\cline { 2 - 5 } & $\begin{array}{l}\text { Ipsilateral } \\
\text { MEP }(\mathrm{ms})\end{array}$ & $\begin{array}{c}\text { Contralateral } \\
\text { MEP }(\mathrm{ms})\end{array}$ & $\begin{array}{c}\text { Ipsilateral } \\
\text { MEP }(\mathrm{ms})\end{array}$ & $\begin{array}{c}\text { Contralateral } \\
\text { MEP }(\mathrm{ms})\end{array}$ \\
\hline Rectus abdominis & $18.8(\mathrm{n}=4)$ & $18.7(\mathrm{n}=13)$ & $21.1(\mathrm{n}=7)$ & $19.5(\mathrm{n}=9)$ \\
& $(18.0-20.8)$ & $(17.5-27.7)$ & $(18.8-45.0)$ & $(16.9-42.0)$ \\
External oblique & $20.3(\mathrm{n}=4)$ & $17.8(\mathrm{n}=12)$ & $19.0(\mathrm{n}=4)$ & $21.2(\mathrm{n}=9)$ \\
& $(19.0-23.3)$ & $(13.0-30.6)$ & $(16.9-22.8)$ & $(16.8-32.2)$ \\
4th thoracic erector spinae & $14.7(\mathrm{n}=5)$ & $12.7(\mathrm{n}=12)$ & $13.2(\mathrm{n}=5)$ & $13.9(\mathrm{n}=10)$ \\
& $(13.0-20.4)$ & $(10.1-27.1)$ & $(9.1-16.6)$ & $(8.5-31.4)$ \\
9th thoracic erector spinae & $15.7(\mathrm{n}=4)$ & $14.0(\mathrm{n}=11)$ & $15.9(\mathrm{n}=3)$ & $16.2(\mathrm{n}=10)$ \\
& $(14.1-17.1)$ & $(10.6-32.5)$ & $(11.2-18.0)$ & $(11.9-30.1)$ \\
\hline
\end{tabular}

Values are median (minimum-maximum)

MEP: Motor evoked potential, n: number of patients evoked in transcranial magnetic stimulation

Table 6. Amplitude of Ipsilateral and Contralateral MEPs Obtained by Stimulation of More Damaged and Less Damaged Hemisphere

\begin{tabular}{lcccc}
\hline & \multicolumn{2}{c}{ Less damaged hemisphere } & \multicolumn{2}{c}{ More damaged hemisphere } \\
\cline { 2 - 5 } & $\begin{array}{l}\text { Ipsilateral } \\
\text { MEP }(\mu \mathrm{V})\end{array}$ & $\begin{array}{c}\text { Contralateral } \\
\text { MEP }(\mu \mathrm{V})\end{array}$ & $\begin{array}{c}\text { Ipsilateral } \\
\text { MEP }(\mu \mathrm{V})\end{array}$ & $\begin{array}{c}\text { Contralateral } \\
\text { MEP }(\mu \mathrm{V})\end{array}$ \\
\hline Rectus abdominis & $215.5(\mathrm{n}=4)$ & $251.0(\mathrm{n}=13)$ & $197.7(\mathrm{n}=7)$ & $201.0(\mathrm{n}=9)$ \\
& $(97.2-1,100)$ & $(78.9-2,100)$ & $(80.0-1,500)$ & $(85.0-1,900)$ \\
External oblique & $345.5(\mathrm{n}=4)$ & $164.1(\mathrm{n}=12)$ & $248.5(\mathrm{n}=4)$ & $343.0(\mathrm{n}=9)$ \\
& $(80.0-586.0)$ & $(56.3-1,900)$ & $(70.5-552.0)$ & $(73.2-1,400)$ \\
4th thoracic erector spinae & $79.5(\mathrm{n}=5)$ & $246.1(\mathrm{n}=12)$ & $205.0(\mathrm{n}=5)$ & $162.5(\mathrm{n}=10)$ \\
& $(53.7-806.0)$ & $(92.8-3,900)$ & $(57.5-947.0)$ & $(73.2-1,900)$ \\
9th thoracic erector spinae & $290.5(\mathrm{n}=4)$ & $206.0(\mathrm{n}=11)$ & $294.0(\mathrm{n}=3)$ & $159.0(\mathrm{n}=10)$ \\
& $(87.9-508.0)$ & $(54.2-1,900)$ & $(64.0-1,100)$ & $(50.5-2,500)$ \\
\hline
\end{tabular}

Values are median (minimum-maximum)

MEP: Motor evoked potential, n: number of patients evoked in transcranial magnetic stimulation

more damaged and less damaged hemisphere due to small sample size and wide range of standard deviation of latency (Table 5). The amplitudes of ipsilateral and contralateral MEPs ranged widely from tens of $\mu \mathrm{V}$ to several $\mathrm{mV}$ (Table 6).

The contralateral MEPs appeared with more damaged and less damaged hemisphere stimulation were recorded in eight from the rectus abdominis muscles, eight from the external oblique abdominal muscles, seven from the 4 th thoracic erector spinae muscles and seven from the 9th thoracic erector spinae muscles. The contralateral MEPs with more damaged hemisphere stimulation had a tendency to exhibit prolonged latencies compared to those with less damaged hemisphere stimulation, but the difference was not statistically significant $(p>0.05)$ (Table
7). In the amplitudes of more damaged hemisphere stimulation and less damaged hemisphere stimulation, there was no statistically significant difference between the two groups $(p>0.05)$ (Table 7).

\section{Correlation between K-BBS score and frequency of MEPs}

The thirteen subjects with a K-BBS score of $\geq 41$ were able to walk independently ${ }^{9,10}$ (mean age : $41 \pm 17$ years), while seven subjects (mean age : $40 \pm 16$ years) with a K-BBS score of $\leq 40$ were unable to walk independently (Table 8). The average K-MMSE score of independent ambulator group was $26.5 \pm 2.8$, and that of dependent ambulator group was $9.0 \pm 6.9$; there was significant intergroup difference $(\mathrm{p}<0.05)$ (Table 8$)$. The contralateral MEPs with more damaged hemisphere stimulation 
Table 7. Latency and Amplitude of Contralateral MEPs Evoked on Both More Damaged and Less Damaged Hemisphere Stimulation

\begin{tabular}{lcccc}
\hline & Latency & \multicolumn{3}{c}{ Amplitude } \\
\cline { 2 - 5 } & $\begin{array}{c}\text { More damaged } \\
\text { hemisphere }\end{array}$ & $\begin{array}{c}\text { Less damaged } \\
\text { hemisphere }\end{array}$ & $\begin{array}{c}\text { More damaged } \\
\text { hemisphere }\end{array}$ & $\begin{array}{c}\text { Less damaged } \\
\text { hemisphere }\end{array}$ \\
\hline Rectus abdominis $(\mathrm{n}=8)$ & 20.2 & 18.3 & 224.8 & 279.5 \\
& $(16 .-42.0)$ & $(15.6-27.7)$ & $(85.0-1,600)$ & $(36.7-2,100)$ \\
External oblique $(\mathrm{n}=8)$ & 21.7 & 19.0 & 316.7 & 213.5 \\
& $(16.8-32.2)$ & $(16.2-30.6)$ & $(73.2-1,400)$ & $(134.0-1,900)$ \\
4th thoracic erector spinae $(\mathrm{n}=7)$ & 13.2 & 12.8 & 188.3 & 369.0 \\
& $(10.4-28.7)$ & $(11.2-27.1)$ & $(86.6-1,900)$ & $(92.8-3,900)$ \\
9th thoracic erector spinae $(\mathrm{n}=7)$ & 16.6 & 13.7 & 205.0 & 312.0 \\
& $(11.9-30.2)$ & $(10.6-32.5)$ & $(50.5-2,500)$ & $(54.2-3,100)$ \\
\hline
\end{tabular}

Values are median (minimum-maximum)

MEP: Motor evoked potential, n: number of patients evoked on bilateral hemisphere transcranial magnetic stimulation

Table 8. Characteristics of Subjects according to Gait Ability

\begin{tabular}{lcc}
\hline & $\begin{array}{c}\text { Independent } \\
\text { ambulator } \\
\text { group }\end{array}$ & $\begin{array}{c}\text { Dependent } \\
\text { ambulator } \\
\text { group }\end{array}$ \\
\hline Number (male/female) & $13(8 / 5)$ & $7(4 / 3)$ \\
Age (years) & $41.1 \pm 17.5$ & $40.4 \pm 16.8$ \\
\hline $\begin{array}{l}\text { Duration from the onset } \\
\text { (months) }\end{array}$ & $27.5 \pm 18.3$ & $29.5 \pm 20.6$ \\
K-MMSE & $26.5 \pm 2.8^{*}$ & $9.0 \pm 6.9^{*}$ \\
\hline
\end{tabular}

Values are mean \pm standard deviation

K-MMSE: Korean-mini mental state examination ${ }^{*} \mathrm{p}<0.05$, Man-Whitney $U$ test test between independent ambulator group and dependent ambulator group

appeared at a frequency of $46-62 \%$ in the 13 independent ambulator group and at a frequency of $29-43 \%$ in the seven dependent ambulator group. The ipsilateral MEPs induced in response to magnetic stimulation of the more damaged hemisphere appeared at a frequency of 15$38 \%$ in the 13 independent ambulator group and at a frequency of $0-29 \%$ in the seven dependent ambulator group. The group of subjects with a K-BBS score of $\leq 40$ showed a low frequency of MEPs compared to the group with a K-BBS score of $\geq 41$, but the difference in frequency between two groups was not statistically significant (p>0.05) (Table 9, 10).

\section{DISCUSSION}

In the previous study of normal subjects, we reported that the ipsilateral and contralateral MEPs with TMS were evoked in trunk muscles at $60-75 \%$ and $100 \%$, respectively. ${ }^{6}$ In this study of patients with TBI, the ipsilateral and contralateral MEPs recorded at the mean frequency of $21.3 \%$ and $60.0 \%$, respectively, with the less damaged hemisphere stimulation. TBI patients showed a lower frequency of ipsilateral and contralateral MEPs both in the more damaged and less damaged hemispheres, compared to normal subjects. When the more damaged hemisphere was stimulated, the ipsilateral and contralateral MEPs in TBI patients were observed at a frequency of $23.8 \%$ and $47.5 \%$, respectively. Compared with normal subjects, such a decrease in the frequency of MEPs in more damaged hemisphere was considered to result from direct injury of the corticospinal projection to trunk muscles. In addition, a decrease in the frequency of MEPs in less damaged hemispheres, it seemed to be associated with injury to the prefrontal cortex, which controls the activity of the corticospinal tract. Gerschlager et al. ${ }^{11}$ reported that the inhibition of premotor cortex decreased the amplitudes of MEPs, and Gennaro et al. ${ }^{12}$ reported that the excitability of the corticospinal tract decreased as a consequence of reduced activity of the prefrontal cortex. These findings suggest that the injury of the prefrontal cortex can be associated with a decrease of MEPs recording from the less damaged hemisphere as well as those from the more damaged hemisphere.

Park et al. ${ }^{7}$ reported that only ipsilateral MEPs but not contralateral MEPs could be evoked with the affected hemisphere stimulation in stroke patients, and they 
Table 9. Percentage of Ipsilateral and Contralateral MEPs in Independent Ambulator Group

\begin{tabular}{lcccc}
\hline & \multicolumn{2}{c}{ Less damaged hemisphere } & \multicolumn{2}{c}{ More damaged hemisphere } \\
\cline { 2 - 4 } & Ipsilateral & Contralateral & Ipsilateral & Contralateral \\
\hline Rectus abdominis $(\mathrm{n}=13)$ & $3(23 \%)$ & $7(54 \%)$ & $5(38 \%)$ & $6(46 \%)$ \\
External oblique $(\mathrm{n}=13)$ & $3(23 \%)$ & $7(54 \%)$ & $4(31 \%)$ & $6(46 \%)$ \\
4th thoracic erector spinae $(\mathrm{n}=13)$ & $4(29 \%)$ & $7(54 \%)$ & $4(31 \%)$ & $7(54 \%)$ \\
9th thoracic erector spinae $(\mathrm{n}=13)$ & $3(23 \%)$ & $7(54 \%)$ & $2(15 \%)$ & $8(62 \%)$
\end{tabular}

MEP: Motor evoked potential, n: number of patients

Table 10. Percentage of Ipsilateral and Contralateral MEPs in Dependent Ambulator Group

\begin{tabular}{lcccc}
\hline & \multicolumn{2}{c}{ Less damaged hemisphere } & \multicolumn{2}{c}{ More damaged hemisphere } \\
\cline { 2 - 5 } & Ipsilateral & Contralateral & Ipsilateral & Contralateral \\
\hline Rectus abdominis $(\mathrm{n}=7)$ & $1(14 \%)$ & $5(71 \%)$ & $2(29 \%)$ & $3(43 \%)$ \\
External oblique $(\mathrm{n}=7)$ & $1(14 \%)$ & $5(71 \%)$ & $0(0 \%)$ & $3(43 \%)$ \\
4th thoracic erector spinae $(\mathrm{n}=7)$ & $1(14 \%)$ & $5(71 \%)$ & $1(14 \%)$ & $3(43 \%)$ \\
9th thoracic erector spinae $(\mathrm{n}=7)$ & $1(14 \%)$ & $4(57 \%)$ & $1(14 \%)$ & $2(29 \%)$ \\
\hline
\end{tabular}

MEP: Motor evoked potential, n: number of patients

suggested that ipsilateral corticospinal projections appear to become unmasked. Similarly, in this study, compared with contralateral MEPs frequency, the more ipsilateral MEPs were found in the rectus abdominis muscles, external oblique abdominal muscles and 4th thoracic erector spinae muscles with more damaged hemisphere stimulation than less damaged hemisphere stimulation in the subjects except the cases where no MEPs were evoked due to serious damage to the motor pathways of trunk muscles. These results suggest that crossed motor pathways that play a major role in motor control before brain injury can be inactivated and the ipsilateral motor pathways that subserve as a suboptimal motor control pre-existing synaptic connections can be activated following TBI. The exact pathway that contributes to the presence of ipsilateral projections to the paretic side following brain injury is not well understood. The most widely recognized ones are unmasked ipsilateral corticospinal and oligosyneptic corticoreticulospinal and corticopropriospinal tracts. ${ }^{13,14}$ In addition, at the spinal level, contralateral axons could sprout terminal connections to the $\alpha$-motor neurons of muscles in the paretic side. ${ }^{13-15}$

Given the fairly constant latency difference, between ipsilateral and contralateral responses of about 1-3 ms obtained in our study, it could be explained that ipsilateral MEPs may be evoked through by uncrossed ipsilateral pathway, which has somewhat slower conduction properties among these projections, such as the corticoreticulospinal tract. Therefore, it is more likely that these ipsilateral motor responses through corticoreticulospinal pathways become unmasked due to a lack of transcallosal inhibition influence after hemispheric lesions. ${ }^{16}$

In this study, the comparisions of MEP latencies and amplitudes were limited because of small sample size and wide range of standard deviation of latency and amplitude.

There has been no study to examine the correlations between trunk muscle MEPs response and trunk muscle performance such as balance or gait ability in TBI patients. In this study, we have attempted to investigate the relationship between the presence of MEP response of trunk muscles and motor performance of trunk muscles with K-BBS in patients with TBI. However, there was no statistical correlation between the response of MEPs in trunk muscles and K-BBS scores. In TBI patients, various factors including visual or vestibular dysfuction, cerebellar damage, cognitive impairment and musculoskeletal problem as well as weakened trunk muscles may underlie balance and gait disturbances. ${ }^{17}$ In this study, the group of subjects with a low K-BBS score received a low score in the K-MMSE as well. This suggests that balance and gait abilities may be affected by 
cognitive function in TBI patients. We could not identify the relationship between MEPs response in the trunk muscle and the trunk muscle performance assessed by K-BBS. However, if data was collected in a large number of TBI patients to assess the response of trunk muscle MEPs and their trunk muscle strength and gait ability, it would help in analyzing the causes of balance or gait disturbance in TBI patients.

\section{CONCLUSION}

This study was designed to examine changes in the motor innervations of trunk muscles in patients with traumatic brain injuries and consequently identified the mechanism of injury to motor pathways of trunk muscles due to brain injury. Although the study did not identify the relationship between the patterns of MEPs in trunk muscles and the clinical recovery of trunk muscle function, the present study sheds a light on the understanding of motor innervations of trunk muscles in patient with traumatic brain injury. Therefore, further studies should draw reliable and generalized conclusions regarding the relationship by investigating motor evoked potentials and clinical scales related to trunk muscle function with more patients.

\section{REFERENCES}

1. Franchignoni FP, Tesio L, Ricupero C, Martino MT. Trunk control test as an early predictor of stroke rehabilitation outcome. Stroke 1997; 28: 1382-1385

2. Hsieh CL, Sheu CF, Hsueh IP, Wang CH. Trunk control as an early predictor of comprehensive activities of daily living function in stroke patients. Stroke 2002; 33: 2626-2630

3. Karatas M, Cetin N, Bayramoglu M, Dilek A. Trunk muscle strength in relation to balance and functional disability in unihemispheric stroke patients. Am J Phys Med Rehabil 2004; 83: 81-87

4. Kim YM, Chun MH, Kang SH, Ahn WH. The effect of neuromuscular electrical stimulation on trunk control in hemiparetic stroke patients. Am J Phys Med Rehabil 2009; 33: 265-270

5. Fujiwara T, Sonoda S, Okajima Y, Chino N. The relationships between trunk function and the findings of transcranial magnetic stimulation among patients with stroke. J Rehabil Med 2001; 33: 249-255
6. Park SH, Seo JH, Song KS, Jeong H. Characteristics of corticospinal innervation of trunk muscles studied with transcranial magnetic stimulation in healthy male. J Korean Assoc EMG-Electrodiagn Med 2007; 9: 133-138

7. Park SH, Song KS, Ko MH, Seo JH. Motor evoked potentials of trunk muscles in stroke patients. J Korean Acad Rehab Med 2009; 33: 282-289

8. Keel JC, Smith MJ, Wassermann EM. A safety screening questionnaire for transcranial magnetic stimulation. Clin Neurophysiol 2000; 112: 720

9. Jung HY, Park JH, Shim JJ, Kim MJ, Hwang MR, Kim SH. Reliability test of Korean Version of Berg Balance Scale. J Korean Acad Rehab Med 2006; 30: 611-618

10. Berg K, Woood-Dauphinee S, Williams JI, David G. Measuring balance the elderly: preliminary development of an instrument. Physiother Can 1989; 41: 304-311

11. Gerschlager W, Siebner HR, Rothwell JC. Decreased corticospinal excitability after subthreshold $1 \mathrm{~Hz}$ rTMS over lateral premotor cortex. Neurology 2001; 14: 449-455

12. Gennaro LD, Marzano C, Veniero D, Moroni F, Fratello F, Curcio G, Ferrara M, Ferlazzo F, Novelli L, Pellicciari MC, et al. Neurophysiological correlates of sleepiness: a combined TMS and EEG study. Neuroimage 2007; 33: 1277-1287

13. Muller K, Kass-Iilyya F, Reitz M. Ontogeny of ipsilateral corticospinal projections: a developmental study with transcranial magnetic stimulation. Ann Neurol 1997; 42: 705-711

14. Sabatini U, Toni D, Pantano P, Brughitta G, Padovani A, Bozzao L, Lenzi GL. Motor recovery after early brain damage. A case of brain plasticity. Stroke 1994; 25: 514-517

15. Benecke R, Meyer BU, Freund HJ. Reorganization of descending motor pathways in patients after hemispherectomy and severe hemispheric lesions demonstrated by magnetic brain stimulation. Exp Brain Res 1991; 83: 419-426

16. Meyer BU, Roricht S, Grafin EH, Kruggel F, Weindl A. Inhibitory and excitatory interhemispheric transfers between motor cortical areas in normal humans and patients with abnormalities of the corpus callosum. Brain 1995; 118: 429-440

17. Basford JR, Chou LS, Kaufman KR, Brey RH, Walker A, Malec JF, Moessner AM, Brown AW. An assessment of gait and balance deficits after traumatic brain injury. Arch Phys Med Rehabil 2003; 84: 343-349 